\title{
Resistência à torção de dois instrumentos endodônticos rotatórios de níquel-titânio
}

\section{Torsional resistance of two nickel-titanium rotatory endodontic instruments}

\author{
Cristiane da COSTA* \\ Marcelo dos SANTOS**
}

\begin{abstract}
COSTA, C. da; SANTOS, M. dos. Resistência à torção de dois instrumentos endodônticos rotatórios de níquel-titânio. Pesq Odont Bras, v. 14, n. 2, p. 165-168, abr./jun. 2000.

Os autores compararam a resistência à torção entre os instrumentos rotatórios de níquel-titânio Quantec Series 2000 e Pow-R, valendo-se de quarenta instrumentos para cada marca divididos em oito para cada um dos seguintes tamanhos $n^{\circ} 15, n^{\circ} 20, n^{\circ} 25, n^{\circ} 35$ e $n^{\circ} 40$ com 21 mm e conicidade .02 . Com a ajuda de um troptômetro modificado cada instrumento foi fixado em um madril e preso à $3 \mathrm{~mm}$ de sua ponta, previamente marcada com uma caneta de tinta permanente, na base do aparelho por uma morsa. Em seguida ativou-se a manivela que continha a escala em graus até notar-se sinal característico da fratura do instrumento registrando-se o valor da quantidade de movimento até este momento. Após tabulação dos dados procedeu-se a análise estatística de acordo com o teste $t$ de Student com nível de significância de $1 \%$. Os resultados mostraram haver diferença estatisticamente significante ao comparar-se limas de mesmo número confrontadas as duas marcas, favorável para o instrumento Pow-R.
\end{abstract}

UNITERMOS: Endodontia; Cavidade da polpa dentária; Instrumentos odontológicos.

\section{INTRODUÇÃO}

Com o objetivo de conseguir uma conicidade continua que acompanhe a forma original do canal radicular e diminuir eventuais acidentes durante a instrumentação, muitos estudos têm sido realizados em torno da confecção de instrumentos endodônticos com mudanças significativas relacionadas principalmente ao tipo de metal utilizado na fabricação dos mesmos. Recentes avanços em tecnologia têm apresentado instrumentos endodônticos produzidos a partir de ligas de níquel-titânio que apresentam propriedades vantajosas em relação às ligas de aço inoxidável, tais como: maior resistência à fratura por torção horária ou anti-horária e maior módulo de elasticidade, que permite voltar a forma original após deformar-se, além da alta flexibilidade.

Esta nova geração de instrumentos endodônticos levou WALLIA et al. ${ }^{10}$ (1988) a iniciar estudos com limas endodônticas de níquel-titânio observando, através de microscopia eletrônica de varredura, que a lima $n^{\circ} 15$ de níquel-titânio apresentou superior resistência à fratura por torção quando comparada com a lima $\mathrm{n}^{\circ} 15$ de aço inoxidável fabricada pelo mesmo processo.

Buscando aumentar a resistência à torção das instrumentos endodônticos SANTOS ${ }^{6}$ (1994) determinou um tratamento térmico recristalizador que diminui o encruamento original da lima, aliviando as tensões induzidas e melhorando a qualidade final do instrumento tornando-o mais seguro, sendo que as limas de níquel-titânio ainda apresentam maior resistência à torção quando comparadas as limas convencionais submetidas ao tratamento recristalizador.

CAMPS; PERTOT ${ }^{2}$ (1994); SERENE et al. $^{7}$ (1995), ROWAN et al. ${ }^{5}$ (1996), WOLCOTT; HIMEL ${ }^{11}$ (1997) foram concordes quando avaliaram a resistência à torção entre limas de aço inoxidável e níquel-titânio, observando que ambas alcançaram ou excederam as especificações da ANSI/ADA $n^{\circ} 281$ (1989), especialmente os instrumentos de níquel-titânio por possuírem propriedades mecânicas que encorajam demais avaliações com estudos clínicos e laboratoriais.

As limas manuais de níquel-titânio não possuem muita eficiência de corte, pois sua alta flexibili-

\footnotetext{
* Especialista em Endodontia, Estagiária de Investigação e Didática; ** Professor Doutor - Disciplina de Endodontia da Faculdade de Odontologia da USP.
} 
COSTA, C. da; SANTOS, M. dos. Resistência à torção de dois instrumentos endodônticos rotatórios de níquel-titânio. Pesq Odont

Bras, v. 14, n. 2, p. 165-168, abr./jun. 2000.

dade não permite que a lima se agarre às paredes do canal promovendo assim pouco desgaste, mas as propriedades metalúrgicas de resistência e elasticidade do níquel-titânio usadas em condições apropriadas e com desenhos anatômicos convenientes fez possivel a confecção de instrumentos endodônticos rotatórios, tornando a limpeza e modelagem do canal radicular mais rápida e eficiente. Pesquisas apresentadas por vários autores como PINEDA; KUTLER ${ }^{4}$ (1997), TEPEL et al. ${ }^{8}$ (1997) e THOMPSON; DUMMER ${ }^{9}$ (1998) têm mostrado serem os sistemas rotatórios promissores quando comparados aos instrumentos manuais.

A resistência à torção dos vários instrumentos endodônticos está relacionada ao processo de fabricação e conformação dos mesmos. As limas e sistemas rotatórios de níquel-titânio são fabricados através de usinagem uma vez que suas propriedades mecânicas não permitem a torção. Quanto a sua forma, as limas de níquel-titânio manuais exibem um desenho semelhante as convencionais, já os sistemas rotatórios basicamente se apresentam com secção de corte transversal triangular, ângulo positivo levemente mais agressivo como o instrumento Pow-R, ou podem se mostrar com desenho tipo U, ângulo de hélice, corte levemente positivo nas duas superficies de trabalho e ponta ativa (SC) ou inativa (LX) com ângulo quase 0 grau que não faz rosca como o sistema Quantec Series 2000.

A variação no desenho dos instrumentos de níquel-titânio fabricados para uso em motores podem determinar comportamentos clínicos muito diferentes em função das propriedades mecânicas determinadas pela diversas formas, o que torna importante o estudo destas diferenças e suas conseqüências.

Assim o presente estudo busca avaliar a resistência à torção de instrumentos rotatórios, Quantec Series 2000 e Pow-R, no intuito de analisar seus comportamentos.

\section{MATERIAL E MÉTODO}

A partir de quarenta instrumentos endodônticos rotatórios Quantec Series 2000 tipo LX, oito para cada um dos seguintes números $\mathrm{n}^{\circ} 15, \mathrm{n}^{\circ} 20$, $n^{\circ} 25, n^{\circ} 35$ e $n^{\circ} 40$, e outros quarenta Pow-R da marca Moyco Union Broach, oito para cada um dos mesmos tamanhos, todos de níquel-titânio com $21 \mathrm{~mm}$ e conicidade .02, foi avaliada a resistência à torção.

Com uma caneta de tinta permanente marcou-se $3 \mathrm{~mm}$ da ponta de cada instrumento, que em seguida foram fixados, um por vez, no mandril de um troptômetro modificado por SANTOS $^{6}$ (1994) segundo modelo de CRAIG; PEYTON ${ }^{3}$ (1962), e presos pela ponta ativa nos $3 \mathrm{~mm}$, em uma pequena morsa existente na base deste aparelho, recoberta com uma lâmina de cobre trocada sempre que apresentava-se marcada pelos instrumentos.

A escala do equipamento foi, inicialmente, calibrada em 0 grau. Acionou-se a manivela acoplada na lateral, torcendo a lima no sentido anti-horário até que se notasse o sinal característico da fratura. A seguir lia-se na escala do aparelho a quantidade de graus percorridos desde 0 grau até o momento da fratura. Os valores registrados neste momento, para cada instrumento, foram anotados e procedeu-se a análise estatística pertinente.

\section{RESULTADOS}

Os resultados das médias do teste de força para os instrumentos avaliados estão expressos na Tabela 1 .

Conforme comparação à curva normal, as amostras apresentaram distribuição dentro da normalidade e assim optou-se pela análise estatística do teste $t$ de Student com um grau de exigência de $\alpha=0,01$.

Os resultados mostram que a resistência à torção dos instrumentos Pow-R foi sempre superior aos Quantec, quando confrontados instrumentos de mesma numeração. As diferenças entre os valores em graus para a resistência à torção entre as duas marcas, sempre dentro da mesma numeração, mostrou diferenças estatísticas significantes ao nivel de $1 \%(\alpha=0,01)$ para todas as comparações.

\section{DISCUSSÃO}

A análise comparativa dos instrumentos núme$\operatorname{ros} \mathrm{n}^{\circ} 15, \mathrm{n}^{\circ} 20, \mathrm{n}^{\circ} 25, \mathrm{n}^{\circ} 35$ e $^{\circ} 40$ entre os sistemas rotatórios Pow- $R$ e Quantec mostrou que os instrumentos Pow-R apresentaram resistência à torção superior provavelmente por terem menor volume de metal na massa de material que susten-

TABELA 1 - Médias da resistência à torção, em graus, dos diferentes instrumentos estudados confrontando-se limas do mesmo número.

\begin{tabular}{c|c|c|c|c|c}
\hline \hline & $\mathrm{n}^{\mathrm{o}} 15$ & $\mathrm{n}^{\mathrm{o}} 20$ & $\mathrm{n}^{\mathrm{o}} 25$ & $\mathrm{n}^{\mathrm{o}} 35$ & $\mathrm{n}^{\mathrm{o}} 40$ \\
\hline Quantec & 399,37 & 398,88 & 363,75 & 434,87 & 361,87 \\
\hline Pow-R & 534,75 & 450,87 & 461,50 & 495,12 & 550,75 \\
\hline \hline
\end{tabular}


COSTA, C. da; SAnTOS, M. dos. Resistência à torção de dois instrumentos endodônticos rotatórios de níquel-titânio. Pesq Odont

Bras, v. 14, n. 2, p. 165-168, abr./jun. 2000.

ta as lâminas de corte, ao contrário do que ocorre com o sistema Quantec que possui aumento da massa metálica tornando maior a rigidez do instrumento e diminuindo a resistência à fratura por torção, compensado pelo benefício de aumentar a eficiência de corte deste instrumento.

O instrumento Quantec possui também, diferentemente do instrumento Pow-R, um ângulo de hélice combinado com espaços criados na lima que aumentam progressivamente à medida que se afastam da aresta de corte, criando uma área de escape maior e fazendo com que os debris sejam removidos do canal rapidamente. Desta forma o instrumento quando acionado não faz rosca, portanto não se agarra as paredes do canal diminuindo o risco de fratura do instrumento por ter um corte menos agressivo e mais eficiente. Assim é natural que o instrumento Pow-R, que possui secção de corte transversal, se atente mais em ter maior resistência à fratura.

Entretanto os instrumentos de níquel-titânio merecem demais avaliações principalmente quanto às modificações conferidas a esta liga durante o processo de fabricação e tipo de secção transversal, como analisou SANTOS ${ }^{6}$ (1994), mostrando a importância da manufatura dos instrumentos endodônticos na resistência final deste.

Autores como WALLIA et al. ${ }^{10}$ (1988) que iniciaram pesquisas com limas de níquel-titânio estimularam muitos outros estudos, até os mais recentes com instrumentos rotatórios de autores como TEPEL et al. ${ }^{8}$ (1997) e THOMPSON; DUMMER ${ }^{9}$ (1998) que concordam ser a liga de níquel-titânio promitente necessitando de mais estudos melhorando, principalmente, os sistemas rotatórios para aplicação na clínica diária.

\section{CONCLUSÕES}

1. Os instrumentos Pow-R mostraram maior resistência à torção que os Quantec quando comparados na mesma numeração.

2. As diferenças entre os resultados das médias da resistência à torção, no sentido anti-horário expressa em graus, entre os instrumentos Pow- $R$ e Quantec, dentro da mesma numeração, foram estatisticamente significativas ao nível de $1 \%$ $(\alpha=0,01)$ de acordo com teste $t$ de Student.

3. Ambos instrumentos excedem a especificação ANSI/ADA $n^{\circ} 28$ para resistência à torção de instrumentos endodônticos.

COSTA, C. da; SANTOS, M. dos. Torsional resistance of two nickel-titanium rotatory endodontic instruments. Pesq

Odont Bras, v. 14, n. 2, p. 165-168, abr./jun. 2000.

The authors compared the torsional resistance between the Quantec Series 2000 and Pow-R nickel-titanium rotatory instruments, using forty instruments of each brand, divided in eight of each one of the following numbers: $n^{\circ} 15, n^{\circ} 20$, $n^{\circ} 25, n^{\circ} 35$ and $n^{\circ} 40$ with $21 \mathrm{~mm}$ and taper .02. Each instrument was fixed in the mandrel of a modified tropometer and held $3 \mathrm{~mm}$ away from its tip, on a spot that had been previously stamped with a permanent ink pen, by apprehension claws localized on the base of the equipment. Then the graduated handle was activated until a characteristic break sign of the instrument was noticed, the quantity of movement up to this moment being recorded. After the values were tabulated, the statistical analysis was carried out according to the Student $t$ test. The results revealed a statistically significant difference when instruments of the same number, from both evaluated brands, were compared, favouring the Pow-R instruments.

UNITERMS: Endodontics; Dental pulp cavity; Dental instruments.

\section{REFERÊNCIAS BIBLIOGRÁFICAS}

1. AMERICAN DENTAL ASSOCIATION. Concil on Dental Materials, Instruments and Equipment. Revised American National Standards Institute. Specification $\mathrm{n}^{\circ} 28$ for root canal files and reamers, type $\mathrm{K}$, and $\mathrm{n}^{\circ} 58$ for root canal files type H (Hedstrom). J Am Dent Assoc, v. 118, n. 2, p. 239-240, Feb. 1989.

2. CAMPS, J.; PERTOT, J. W. Torsional and stiffness properties of canal master $U$ stainless steel and nitinol instruments. J Endod, v. 20, p. 395-398, Sept. 1994.

3. CRAIG, R. G.; PEYTON, F. A. Physical properties of carbon steel root canal files and reamers. Oral Surg, v. 15, n. 2, p. 213-226, Feb. 1962.

4. PINEDA, F.; KUTTLER, S. Una nueva solución para llegar al ápicce: el RBS. Moyco Union Broach. Facts 1997.

5. ROWAN, B. M.; NICHOLLS, I. J.; STEINER, J. Torsional properties of stainless steel and nickel-titanium endodontic files. J Endod, v. 22, n. 7, p. 341-345, July 1996.

6. SANTOS, M. Avaliação comparativa do comportamento, diante de ensaio de torção, de limas endodônticas de diferentes tipos, marcas e números, submetidas ou não a um tratamento térmico recristalizador. São 
COSTA, C. da; SANTOS, M. dos. Resistência à torção de dois instrumentos endodônticos rotatórios de níquel-titânio. Pesq Odont Bras, v. 14, n. 2, p. 165-168, abr./jun. 2000.

Paulo, 1994, 76 p. Tese (Doutorado) Faculdade de Odontologia, Universidade de São Paulo.

7. SERENE, P. T.; ADAMS, D. J.; SAXENA, A. Nickel-titanium instruments: aplications in endodontics. Ishiyaku EuroAmerica, Inc., 1995.

8. TEPEL, J.; SCHAFER, E.; HOPPE, W. Properties of endodontic hand instruments used in rotary motion. Part 3. Resistance to bending and fracture. J Endod, v. 23, n. 3, p. 141-145, Mar. 1997.

9. THOMPSON, S. A ; DUMMER, P. M. H. Shaping ability of
Mity Roto 360 and Naviflex rotary nickel-titanium instruments in simulated root canals. Part 1. J Endod, v. 23, p. 128-142, 1998.

10. WALLIA, H.; BRANTLEY, A. W.; GERTEIN, H. An initial investigation of the bending and torsional properties of nitinol root canal files. J Endod, v. 14, n. 7, p. 346-351, 1988.

11. WOLCOTT, J.; HIMEL, T. V. Torsional properties of nickel-titanium versus stainless steel endodontic files. J Endod, v. 23, n. 4, p. 217-220, Apr. 1997.

Recebido para publicação em 12/08/99 Enviado para reformulação em 02/12/99 Aceito para publicação em 02/02/00 